\title{
O Imperativo da Autonomia: Uma Leitura Crítica a partir da Psicanálise
}

\author{
Suéllen Pessanha Buchaúl* \\ Pontifícia Universidade Católica do Rio de Janeiro - PUC-RJ, Rio de Janeiro, RJ, Brasil \\ ORCID: https://orcid.org/0000-0001-9950-4919 \\ Maria Isabel Fortes** \\ Pontifícia Universidade Católica do Rio de Janeiro - PUC-RJ, Rio de Janeiro, RJ, Brasil \\ ORCID: https://orcid.org/0000-0003-3662-9575
}

\begin{abstract}
RESUMO
O presente artigo apresenta a questão sobre o modo imperativo com o qual se instituiu a figura da autonomia no discurso social e a crítica da psicanálise enunciada por Jacques Lacan. Para isso faremos algumas considerações acerca da noção de autonomia: primeiro como herança da modernidade e depois como um modo de subjetivação na cultura contemporânea, investido de intenso sentimento de angústia. A aspiração moderna pela autonomia converteuse na atualidade como um imperativo, promovendo efeitos no sujeito. $\mathrm{O}$ ensino lacaniano, em seu início, aponta à ineficiência sobre a promoção social da autonomia, uma vez que a concepção de sujeito do inconsciente subverte a ideia de indivíduo autônomo. A partir da relação entre demanda e desejo, considerando a divisão do sujeito pela ordem da linguagem e o eu situado no registro do imaginário, a psicanálise intenta o imperativo social em busca da autonomia como um discurso delirante ao sujeito do inconsciente.
\end{abstract}

Palavras-chave: autonomia, imperativo, subjetivação, psicanálise, sujeito.

\section{The Imperative of Autonomy: A Critical Reading from Psychoanalysis}

\begin{abstract}
This article presents the question about the imperative way in which the figure of autonomy was established in social discourse and the critique of psychoanalysis enunciated by Jacques Lacan. For this, we will make some considerations about the notion of autonomy: first as a legacy of modernity and then as a way of subjectivation in contemporary culture, invested with an intense feeling of anguish. The modern aspiration for autonomy has now become an imperative, promoting effects on the subject. Lacanian theory, at its beginning, points to the inefficiency over the social promotion of autonomy, since the concept of the subject of the unconscious subverts the idea of an autonomous individual. From the relation between demand and desire, considering the subject's division by language order and the ego located in the imaginary register, psychoanalysis intends the social imperative in search of autonomy as a delusional discourse to the subject of the unconscious.
\end{abstract}

Keywords: autonomy, imperative, subjetivation, psychoanalysis, subject.

ISSN $1808-4281$ 


\section{El Imperativo de la Autonomía: Una Lectura Crítica del Psicoanálisis}

\section{RESUMEN}

Este artículo presenta la cuestión sobre la forma imperativa con que se estableció la figura de la autonomía en el discurso social y la crítica al psicoanálisis enunciada por Jacques Lacan. Para ello, haremos algunas consideraciones sobre la noción de autonomía: primero como legado de la modernidad y luego como forma de subjetivación en la cultura contemporánea, investida de un intenso sentimiento de angustia. La moderna aspiración a la autonomía se ha convertido ahora en un imperativo, promoviendo efectos sobre el sujeto. La enseñanza lacaniana, en sus inicios, apunta a la ineficacia sobre la promoción social de la autonomía, ya que el concepto de sujeto del inconsciente subvierte la idea de individuo autónomo. A partir de la relación entre demanda y deseo, considerando la división del sujeto por el orden del lenguaje y el yo ubicado en el registro imaginario, el psicoanálisis entiende el imperativo social en busca de la autonomía como un discurso delirante al sujeto del inconsciente.

Palabras clave: autonomía, imperativo, subjetivación, psicoanálisis, sujeto.

A busca por modelos subjetivos de performance e de iniciativa individual tem sido recorrente no cenário contemporâneo. Como herança do discurso racionalista moderno, o ideal para ser um indivíduo autônomo tornou-se uma exigência da massa cultural, impregnada nos discursos populares, nas instituições escolares, nas empresas e chegando, evidentemente, aos consultórios de psicanálise. A carga de sofrimento gerada pela imposição do discurso social sobre a autonomia é de tal maneira internalizada pelo indivíduo passando, portanto, a uma obrigação particular, individual e de competitividade entre os pares (Ehrenberg, 2010). Esse modelo, inspirado pelo contexto sociocultural e histórico da modernidade, exige do sujeito um papel o qual ele normalmente não se encontra em condições de sustentar, ou seja, o lugar de mestre de si mesmo (Hoffman, 2005).

Com efeito, o imperativo à autonomia como discurso social tem desencadeado novas configurações psicopatológicas como o sentimento de insuficiência, sentimento de tristeza e sensação de vazio aumentando, por assim dizer, a incidência de queixas de quadros de depressão como assinala o sociólogo Ehrenberg (1998). Em seu livro, "La fatigue d'être soi: dépression et société”, o autor desenvolveu um estudo a fim de evidenciar a relação entre a sintomatologia da depressão e a questão do discurso imperativo da autonomia. Sua análise chamou atenção para o valor persuasivo com o qual se dissemina o discurso da "autonomia" comparando-o com o dispositivo disciplinar, operador central na modernidade, enfatizado por Foucault (1978-79/2008) referente àquele ethos social. 
Entretanto, a crítica de Ehrenberg $(1998,2010)$ sobre o imperativo social da autonomia não é novidade para a Psicanálise. Em meados do século passado, Lacan (195455/1985a) já havia apontado que a ambição por uma independência total do campo do outro revela-se como algo inalcançável, de modo que esse discurso não poderia ser outra coisa senão um discurso delirante. O discurso do ideal moderno de autonomia, cuja a ideia gira em torno do protótipo "mestre de si mesmo", confere a um Eu central, racional e totalmente organizado por sua consciência. Segundo a psicanálise o sujeito não consegue alcançar esse ideal, uma vez que o inconsciente revela como instância descentralizada, autônoma e independente ao Eu. À medida que o Eu está no registro do imaginário, das ilusões, da alienação, das identificações entre pares, o sujeito do inconsciente está situado no registro simbólico, no campo da linguagem, regido pela cadeia significante e precedido pelo Outro.

Procuraremos, através deste artigo, apresentar a crítica da psicanálise a partir da leitura lacaniana do Seminário, livro 3: as psicoses, no início de seu ensino, onde o autor compara o imperativo social à autonomia com um discurso delirante.

\section{A Concepção de Autonomia como Herança Moderna}

No início da modernidade, passagem do século XVI para o século XVII, quando surge o racionalismo inaugurado por Descartes (1641/2005), filósofo que rompe com a filosofia da Idade Média, a existência do homem afirma-se mediante sua condição de ser pensante. A célebre expressão "Cogito, ergo sum”, traduzida do latim por "penso, logo existo", apresenta essa certeza indubitável diante de todas as outras coisas e o homem passa a considerar-se o ser central do universo, constituído de um Eu que subsiste mediante sua capacidade de pensar.

O novo paradigma cartesiano levou à destituição do papel central e onipotente da divindade no mundo, sendo um dos fatores principais que impulsionou mudanças estruturais no ocidente desembocando na grande revolução científica que marcou o final do século XVII e a entrada do século XVIII (Dumont, 1983).

A revolução científica, juntamente com a chegada da revolução industrial - sustentada pelo modo de produção capitalista -, desencadearam uma nova configuração social que foi o estabelecimento da sociedade burguesa capitalista (Engels \& Marx, 1848/2005). Foi dessa maneira que a revolução social começou a se propagar com o firmamento de mudanças ideológicas que passaram a emergir e se estabelecer nessa época. Não iremos destrinchar cada parte histórica, embora sua reconhecida importância. O que pretendemos é tão somente nos 
restringir aos pontos simbólicos decorrentes da passagem dos séculos, a fim de situarmos historicamente a gênese do ideal a respeito da autonomia.

A sociedade ocidental europeia do século XVIII foi palco do movimento filosófico do Iluminismo, cuja bandeira era a razão acima de tudo - efeito do cogito cartesiano. Nesse período, século das Luzes, "a racionalidade vai desenvolver-se como razão construtiva das teorias e como razão crítica (...) a ideia de um universo totalmente acessível ao racional, assim como a concepção de uma humanidade guiada pela Razão" (Morin, 2005, p. 24). Os avanços científicos e os aspectos racionalistas passaram a ser valorizados, visando o progresso da Humanidade a partir da perspectiva de tornar o homem mais evoluído e, por este meio, criar uma sociedade mais avançada em termos civilizatórios.

O final do século XVIII poderia ser compreendido como "um esplêndido nascer do sol” (Morin, 2005, p. 25). Há, nessa expressão, a correlação direta entre a razão e a luz, aquilo que é iluminado. A ideia norteadora dessa época consiste em o homem ser capaz de transformar a sociedade e direcionar o seu próprio destino. O lema, portanto, seria a figura de um indivíduo livre e independente, capaz de explorar o mundo a seu próprio modo, o que forneceu as bases para o individualismo moderno. De fato, foram as ambições de liberdade e independência - princípios que contribuíram para a emergência da revolução social -, que fizeram surgir o movimento do individualismo, mapeado de maneira ao mesmo tempo extensa e precisa pelo sociólogo francês Dumont (1983).

Dumont (1983) descreveu a sociedade individualista como uma organização social composta de elementos singulares, na qual cada um deveria se desenvolver de modo independente a fim de agregar maior valor à sociedade. À esteira disso, surge o movimento liberal que, implicitamente, chega emparelhado pelo sistema capitalista. Neste contexto, as instituições como escolas, fábricas e outras instâncias sociais começam a se programar para formar um indivíduo que possa responder ao novo ideal. Desse modo, o advento da sociedade capitalista burguesa e do regime liberal faz eclodir a ideologia individualista.

À medida que o sujeito deseja buscar sua ascensão econômica e pessoal com o horizonte de alcançar liberdade e independência, a noção de individualismo se intensifica cada vez mais na cultura ocidental. E se fortalece ainda mais com o passar dos anos, das décadas, dos séculos. Surge, assim, um modo de se subjetivar pressionado a ser autossuficiente, acreditando na possibilidade de alcançar sua liberdade e independência e, desse modo, de ter completa autonomia. Contudo, esse bem supremo não parece ser tão acessível ao sujeito. Dumont (1983) esclarece que a inviabilidade da noção de individualismo está, justamente, na ideia que foi se firmando: de um indivíduo supostamente autossuficiente, 
autônomo e capaz de total independência - ideia que, afinal, inverte a própria noção de sociedade.

Curioso notar que a noção de individualidade era necessariamente cernida pelo princípio de igualdade. As condições sociais oferecidas para a ascensão do sujeito eram sustentadas pela doutrina cristã com o preceito de uma sociedade "justa" e "igual" para todos. Caberia, portanto, ao indivíduo ser capaz de aproveitar as oportunidades oferecidas pela sociedade para conquistar seu lugar social. Aquele que não conseguisse se estabelecer no campo social e econômico era considerado um sujeito "incapacitado". Tal paradoxo produzido pela ideologia da época revela uma discrepância entre o discurso social transmitido ao sujeito e as condições que eram exigidas dele. Não à toa, Dumont (1983) nomeou essa problemática de diferença de valor. Dito de outro modo, seria através do indivíduo que a sociedade poderia se transformar e ser valorizada.

Apesar disso, a noção de individualismo foi ganhando terreno e se consolidando com a presença maciça do cristianismo, juntamente com o fortalecimento do capitalismo. Um princípio prometeico no qual o processo de produção subjetiva passou a ser controlado por discursos que instituíram parâmetros de comportamentos, estilos de vida e de relações etc., em razão do direito à liberdade. Com isso, a passagem do século XVIII para o XIX demarcou a preeminência das relações de poder sobre o funcionamento da organização econômica, política, cultural e social, transformando também os modos de subjetivação.

Foucault (1975/1987) problematizou esse contexto apontando que os corpos passaram a ser moldados pelo dispositivo capitalista sob a forma do que ele chamou de biopoder. Esse termo, tão conhecido e enunciado pelo filósofo francês, representa o domínio das relações de poder sobre os corpos individuais, imiscuindo-se como um processo subjetivo. Com o desenvolvimento tecnológico e da ciência, esse complexo maquínico passa a operar de forma mais abrangente, incidindo sobre os corpos de maneira coletiva - instrumento que foi designado por Foucault sob o termo de biopolítica (Foucault, 1978-79/2008).

A biopolítica consiste em um dispositivo de poder que alcança parte significativa da sociedade, produzindo formas e modos de subjetivação. A dinâmica de relações de poder atravessa o corpo social e emprega o indivíduo no campo político sob os mecanismos de força e de submissão. O corpo é transformado em um objeto a ser administrado, passando a ser um utensílio submetido à tecnologia de poder. A dominação e a submissão dos corpos, portanto, tornam-se elementos fundamentais para o processo de relações de poder que marcaram a passagem do século XIX para o início do século XX (Foucault, 1975/1987). 
A tese foucaultiana mostra a ferocidade com que o poder disciplinar incide sobre a sociedade moderna, sinalizando o exercício das forças de punição, correção e enquadramento sobre o sujeito. Sua crítica baseia-se na ideia de que os dispositivos de controle fortalecidos pela emergência do capitalismo visam os corpos como meios de produção. Em meio a essa configuração social, o coletivo, impulsionado pelo discurso normalizador, ganha destaque e empoderamento sobre a subjetividade individual. Para Foucault (1978-79/2008), os sujeitos passaram a ser enquadrados em um modo único de controle político, social, econômico e moral.

\section{A Autonomia como Modo de Subjetivação e de Existência}

A grande virada que caracteriza os meados do século XX é que os modos de produção capitalista não funcionam mais unicamente no registro dos valores de troca - valores que são da ordem do capital -, mas passam a funcionar, principalmente, por meio do controle da subjetivação, influenciando todo o modo de existência. Deleuze (1972/1992) aponta que a subjetividade é fomentada por meio dos modelos de existência que são disseminados pelo capital social. Para o autor, trata-se da grande máquina industrial que captura a subjetividade como natureza industrial e de produção. O que passa a ser colocado em pauta são modos de existência estritamente vinculados aos interesses capitalistas, determinando, por exemplo, o que é ser criança, como ser boa mãe, como ser bom pai, como ser livre, ter autonomia etc.

O engodo que marca esse paradigma é a crença a ele subjacente de que se teria total liberdade de escolha, sem saber que no fundo se obedece a um modo de existência produzido pelo sistema. Deleuze (1972/1992) ressalta que o capitalismo social atua como controle no nível da liberdade de escolha dos sujeitos, situando-os dentro de um determinado modo de controle contínuo, de formação permanente, atuando no nível da nossa liberdade que se estende de forma crescente até nossos dias. A rede de controle diz o que você deve escolher e, então, você escolhe com prazer! Com o assentamento da globalização devido ao avanço das tecnologias de informatização e comunicação (TICs) e com o progresso acelerado da ciência, esse discurso vai se difundindo de modo cada vez mais instantâneo e, ao mesmo tempo, cada vez mais sorrateiro e insidioso. A este enquadre social Deleuze batizou de sociedade do controle.

O modelo de controle dos modos de subjetivação descrito acima envolve as noções de liberdade e de autonomia as quais, conforme já evidenciado, surgem com matizes específicas na ideologia individualista. Após a virada do século XX, esse mito se expande pelo espaço 
social. A contemporaneidade consiste, justamente, nesse novo objeto de valor mercadológico do capitalismo: a subjetividade humana. Dessa maneira, a ideologia neoliberal retoma o princípio do liberalismo e intensifica ainda mais àquela ideia de liberdade individual (Harvey, 2008). Dado que, para sobreviver, por um lado, em uma sociedade na qual Deus foi destituído de seu papel como pai eterno e, por outro, em um Estado que não sustenta sua função como regulador do controle social, o sujeito precisa adquirir sua independência. $\mathrm{O}$ que entra em jogo agora não é mais uma noção de liberdade associada a um valor social, mas uma autonomia como um modo de sobrevivência. O ideal de autonomia surge aí como uma condição e não mais (e não somente) como aspiração (Ehrenberg, 2010).

No livro "La société du malaise", Ehrenberg (2010) investiga dois aspectos do ideal de autonomia - como condição e como aspiração - na sociedade europeia, em especial na França no período entre a Revolução Francesa e o final da Segunda Guerra Mundial. De acordo com sua análise, o ideal de autonomia tem sua gênese no final do século XVIII, marcada pelo liberalismo, inflexão do individualismo. $\mathrm{O}$ autor mostra que, em um primeiro momento, o ideal de autonomia eclode como aspiração coletiva, significando independência do indivíduo. Como vimos, esse ideal emerge com uma perspectiva de ordem e progresso social. Porém, em um segundo momento, devido à falência do Estado, o valor de autonomia ressurge amparado pelo regime neoliberal como uma condição de sobrevivência e disputa entre classes. Dessa maneira, retorna de forma acentuada no período pós-guerra, com o movimento neoliberal configurando um modo de subjetivação no espaço social e individual sob o prisma de um ideal de liberdade - condição considerada essencial para o alcance da felicidade.

Nesse período, surgiram diversos e variados estudos sociológicos para "diagnosticar" as causas das transformações sociais, culturais e econômicas que, de certa forma, levaram a mudanças significativas na sociedade.

Em Frankfurt, Adorno e Horkheimer (1947) denunciaram que o progresso da cultura teve seu fluxo não pela cultura de massa, mas pela capitalização da "indústria cultural". Nos anos de 1960, Guy Debord publica "A sociedade do espetáculo”. Obra essencialmente crítica, discorre sobre o domínio avassalador do modo de produção capitalista em relação à organização social na Europa. Debord (1967/1992) recorre ao termo "fetichismo mercadológico" de Marx para sinalizar o recrudescimento do poder socioeconômico e cultural do capitalismo. Para ele, a sociedade ganha caráter de espetáculo, uma vez que a classe burguesa passa a ter na imagem o elemento central que organiza as suas relações: " $O$ espetáculo não é um conjunto de imagens, mas uma relação social entre pessoas, mediada por imagens" (Debord, 1967/1992, p. 10). Tal característica da classe burguesa tem forte 
ascendência sobre a proletária, incitando-a também à prática do consumo em privilégio próprio, prática que fascina o mercado.

Complementando as ideias de Debord sobre esse cenário, Jean Baudrillard lança, em 1970, o livro “A sociedade de consumo". Nesta obra, o sociólogo francês faz referência diretamente à questão do consumo mediada pelos meios de comunicação de massa. Baudrillard (1970/2008) chama atenção para a forma como é disseminada a ideia de consumo: haveria um exercício de manipulação de signos instituídos socialmente como um "sistema de valores que assegura a ordenação dos signos e a integração do grupo" (p. 91).

Nessa mesma perspectiva, podemos citar, ainda, o historiador americano Christopher Lasch, o qual, em 1979, publicou "A cultura do narcisismo: a vida americana numa era de esperanças em declínio”. Trata-se de uma análise da sociedade americana afetada pela globalização, na qual o autor apresenta ideia de uma ética de sobrevivência narcísica, em função da queda dos ideais e da crise do Estado (Lasch, 1979/1991). Por conta da falta de condições oferecidas pela sociedade capitalista, o indivíduo, não tendo mais com quem contar, teria que procurar lidar com o caos por si mesmo.

Além dos citados, há ainda o ensaio a "Sociedade de risco", de autoria do sociólogo alemão Beck (1986/2010). Ali, o autor denuncia que o movimento pós-revolução industrial desencadeia modalidades de risco à sociedade e às suas instituições, como a instituição familiar. Seu argumento se baseia no papel individualista que o indivíduo passa a priorizar, secundarizando a função das instituições sociais (Beck, 1986/2010).

\section{A Presença da Figura da Autonomia como Imperativo na Atualidade}

$\mathrm{Na}$ medida em que o sujeito foi buscando sua ascensão econômica e pessoal, a ideologia do individualismo foi, paralelamente, se intensificando na cultura ocidental. Com o passar do tempo, a ideia da possibilidade de o indivíduo ser autossuficiente, livre e autônomo foi ficando cada vez mais peremptória. Como vimos, a aspiração pela liberdade, assim como o ideal de autonomia que a acompanha, começa a causar maior impacto social com o desdobramento do individualismo em sua versão do regime neoliberal - firmando-se, ainda, com os avanços da globalização e das tecnologias de informação e comunicação (Lemos, 2016).

Nessa perspectiva, a pujança por um ideal de ser autônomo, livre e autêntico tornou-se mais intenso, a ponto de essa (auto)exigência ser apelidada por Ehrenberg (1998) como uma "doença" comparável à depressão. Expressão que refere a um estado de insuficiência no qual 
o sujeito contemporâneo encontra-se por não conseguir atender ao imperativo social, que o incita à autonomia como modo de felicidade plena. Haveria, de acordo com o autor francês, uma relação entre o crescente número de diagnósticos de depressão e a significativa exigência de iniciativa individual e de performance delegada ao sujeito. Assim, a depressão - antes considerada como o mal do século -, é por ele concebida agora como uma patologia relacionada à autonomia.

Ehrenberg (1998) ressalta que o ideal de autonomia se tornou, na atualidade, uma exigência sociocultural que atravessa o sujeito de modo avassalador. É preciso realçar isto: a contemporaneidade é marcada por uma contradição de termos, na medida em que ser autônomo não é uma questão de escolha, mas de imperativo. Há um imperativo da autonomia que pressiona em direção a tornar-se cada vez mais autossuficiente, o que vem acarretando um mal-estar intenso na contemporaneidade.

Segundo o autor, "ser autônomo" implica em ações e tomada de decisões pessoais sobre as quais o sujeito nem sempre se encontra pronto a realizar. Nesse caso, ele é convocado a dar conta de tudo e, quando não consegue, é tomado por um sentimento de incapacidade, insuficiência, tristeza, depressão.

Para Ehrenberg (2010), o ideal de autonomia é engendrado no espaço social como um dispositivo de poder, assim como foi a disciplina para a modernidade. Ele é introduzido por meio de mecanismos institucionais, através das mais eficientes técnicas de informação e de comunicação, estando presente nas escolas, nas organizações, nas redes sociais etc. Parafraseando Foucault (1978-79/2008), esse ideal chega com um discurso como produção de verdade carregado de efeitos sobre o sujeito, com todo o tipo de variações possíveis.

\section{A Crítica da Psicanálise frente ao Imperativo Social à Autonomia}

Desde a sua inauguração, a psicanálise caminha na contramão da concepção de sujeito cartesiano, centrado num eu totalmente consciente e pensante. A psicanálise surge, entre o final do século XIX e início do século XX, como um método de tratamento para o psiquismo, sobretudo, na questão relacionada ao mal-estar. Ao revelar o inconsciente como uma instância psíquica, Freud (1917/1996) aponta para um novo paradigma sobre o qual o homem não é todo consciente de si, nem, tampouco, passível de total autocontrole.

No ensino de Jacques Lacan, o termo autonomia aparece de relance, mais especificamente, no Seminário, livro 3: as psicoses, onde ele aproxima a ideia de autonomia com a do pensamento paranoico. Lacan (1955-56/1985b) relaciona a aspiração do sujeito à 
autonomia com o imperativo social do discurso de individualismo. Esse discurso é consolidado no meio social em consequência, como vimos, da ideologia do neoliberalismo, sendo considerado por Lacan como um discurso delirante, ou seja, como da ordem do impossível para o sujeito neurótico.

Para Lacan (1955-56/1985b), pensar a ideia de um sujeito completamente autônomo caminha, antes de qualquer coisa, na contramão da sua teoria, pois conota a ideia de liberdade e de independência em relação ao Outro, presumindo consequentemente a visão de um ser "autossuficiente". Ao contrário dessa concepção, a psicanálise sustenta o conceito de sujeito dividido - em termos lacanianos, de sujeito barrado pelo significante. Sendo assim, a perspectiva de um sujeito autônomo é alvo de crítica na abordagem lacaniana.

Se consideramos a autonomia próxima à ideia de um eu livre, centrado e consciente de si - ou seja, alusivo ao discurso cartesiano -, então essa compreensão é totalmente subvertida pela psicanálise. Isso porque, desde Freud, a psicanálise propõe a ideia de um eu descentrado, ideia segundo a qual "o ego não é o senhor na sua própria casa" (Freud, 1917/1996, p. 178). É nesse sentido que a expressão "sujeito do inconsciente" surge derivada da subversão do sujeito do cogito cartesiano. Ao invés do eu, é o inconsciente que se situa na dimensão psíquica (Lacan, 1954-55/1985a).

A formação do eu, de acordo com a teoria lacaniana, se constitui a partir da relação especular, ou seja, da relação imaginária com o outro. Em seu "Seminário, livro 2: o eu na teoria de Freud e na técnica da psicanálise", Lacan (1954-55/1985a) afirma: “o ego nunca é apenas o sujeito", mas se constitui na relação com o outro que "ele toma como ponto de partida e de apoio" (p. 224). Foi a partir do próprio cientificismo de Descartes que emergiu o sujeito da psicanálise, a própria noção cartesiana de sujeito pensante e consciente de si que possibilitou a Freud elaborar sua concepção de inconsciente (Lacan, 1965/1998b). Desse modo, o eu, para a psicanálise, não é central, mas dividido, inclusive sendo em sua maior parte inconsciente (Freud, 1923/1996). É justamente a diferença entre aquilo que o eu quer enunciar e aquilo que o sujeito, efetivamente, enuncia, que vem fazer furo no que podemos chamar de cientificismo cartesiano.

Com efeito, para Lacan, o sujeito do inconsciente está situado "para além do ego" (Lacan, 1954-55/1985a, p. 221). O imperativo ao ideal de autonomia esbarra no processo de constituição do sujeito e, neste sentido, faz-se impossível pensar que ele basta a si próprio:

O eu não se reduz a uma função de síntese. Ele está indissoluvelmente ligado a esse tipo de mão morta, de parte enigmática necessária e insustentável, que constitui em 
parte o discurso do homem real com quem lidamos em nossa experiência, esse discurso estranho no seio de cada um enquanto ele se concebe como indivíduo autônomo. (Lacan, 1955-56/1985b, p. 157, grifos nossos)

Isso nos leva a evocar o paradoxo entre demanda e desejo que marca as primeiras etapas da evolução libidinal, através da operação de um dispositivo ao qual denominou-se na psicanálise de castração (Freud, 1915/1996; Lacan, 1960-61/1992). O sujeito do inconsciente é, tal como foi enunciado por Freud, marcado pela falta, e concebido, de acordo com Lacan, como um sujeito barrado (\$) pelo significante. Essa concepção de constituição do sujeito foi desenvolvida na teoria lacaniana com base na relação do encontro entre o sujeito e o Outro, inscrita a partir da articulação entre o sujeito e a lógica significante na dimensão dialética do objeto e da problemática do desejo (Lacan, 1954-55/1985a; 1960-61/1992).

Freud (1915/1996) marca o descentramento do sujeito e Lacan (1960/1998) o define como dividido pela ordem da linguagem, representado pela cadeia significante. Ao lançar a noção de objeto $a$ como causa de desejo e conceber uma falta estrutural na constituição subjetiva, o ensino lacaniano sustenta a ideia de um sujeito constituído como um falta-a-ser. Dessa forma, o sujeito do desejo se constitui a partir de um vazio fundamental, quer dizer, alguma coisa na origem de sua constituição escapa à formação de uma unidade. Em consequência disso, o sujeito do inconsciente falha no que diz respeito à noção de "todoconsciente de si" (“selbstbewusstsein") (Lacan, 1953-54/1986).

O ser humano foge do esquema etológico (comportamento animal), no qual haveria um ciclo que se refere à satisfação da necessidade diante de um determinado objeto (Lacan, 1953-54/1986). Ao contrário disso, o ciclo entre desejo e satisfação é, no homem, inesgotável. Portanto, sua relação com a natureza é alterada. Esse ciclo é, de todo modo, indefinível, porque o desejo está para além de sua necessidade. Como nos afirma Lacan, “o rompimento do círculo do 'innenwelt' para o 'umwelt' gera a quadratura inesgotável dos arrolamentos do eu" (Lacan, 1949/1998a, p. 100). Os termos "innenwelt" e "umwelt", na língua alemã, fazem referência ao mundo interno e ao ambiente ou mundo externo, respectivamente. Lacan utilizaos para "estabelecer uma relação do organismo com sua realidade", a qual - ele mesmo afirma - que "o homem escapa” (Lacan, 1949/1998a, p. 100).

Dessa maneira, a tese freudiana de sujeito do inconsciente foi mantida por Lacan com a ideia de sujeito barrado, $\$$, segundo a qual a relação entre demanda e desejo está para além de sua necessidade e de suas tendências naturais. 
Diante daquilo que limita o sujeito à plena satisfação, ele se encontra permanentemente na procura da resposta sobre "Quem sou?", cuja resposta, para a psicanálise, sabemos não haver! Destarte, Lacan aponta essa problemática a respeito do enigma sobre a existência do sujeito, no sentido de que ela gira em torno do modo como ele se relaciona com o seu desejo. Essa operação se deve à maneira pela qual o sujeito se articula com o Outro, assim como a mobilidade que ele é capaz de fazer em relação ao seu gozo.

É nessa direção que Lacan problematiza as questões "Eu existo?" ou "Eu não existo?", situando o desejo na relação em que o sujeito se articula com o significante a partir do grafo do desejo. Tal operação é feita na constituição do sujeito, percorrendo o estágio do espelho, o complexo de castração, a construção da fantasia e a inconsistência do Outro. É por meio da inconsistência do ser, apresentada no ensino lacaniano, que podemos compreender sua leitura que entende o discurso da autonomia como ilusão.

Lacan (1955-56/1985b) afirma que o discurso de liberdade expressa a aspiração do sujeito de buscar ser livre e independente. Completa que esse anseio se fortalece com a ideologia social que concede ao sujeito o direito de pensar a possibilidade de conquistar sua autonomia. O psicanalista aponta para a relação entre esse ideal social sobre o discurso de liberdade e a angústia remetida ao sujeito.

Como dito, ao aspirar pela liberdade e independência, ele se vê impossibilitado e, consequentemente, frustrado. Aqui, Lacan alerta para aquilo que Ehrenberg (1998, 2010) enfatizaria anos depois: os efeitos subjetivos gerados pela frustração de não alcançar o ideal social de autonomia. É nesse aspecto que Lacan situa a questão principal da psicanálise. O discurso que trata de um ideal à autonomia foi por ele considerado como um discurso delirante, por referir-se a algo da ordem do impossível ao sujeito do inconsciente. Em suas palavras:

A psicanálise não se coloca nunca no plano do discurso da liberdade, mesmo que este esteja sempre presente, constante no interior de cada um, com suas contradições e discordâncias, pessoal embora sendo comum, e sempre, imperceptivelmente ou não, delirante. A psicanálise visa, aliás, o efeito do discurso no interior do sujeito. (Lacan, 1955-56/1985b, pp. 156, grifos nossos)

Essa reflexão fez Lacan remeter a ideia de autonomia a um discurso de delírio, como o delírio de onipotência presente na paranoia e, sobretudo, na megalomania. Vimos que o discurso imperativo de liberdade está associado ao ideal de autossuficiência, e que, 
impossibilitado de responder a esse ideal, o sujeito sofre com uma sensação de insuficiência (Ehrenberg, 1998, 2010). Lacan teve, em sua época, uma leitura semelhante, mas pensando a radicalidade desse ideal como sinônimo de uma independência plena em relação a tudo e a todos: o homem, ao afirmar "sua independência em relação, não só a todo senhor, mas também a todo deus ... sua irredutível autonomia como indivíduo, como existência individual", cai na armadilha dessa ideologia social (Lacan, 1955-56/1985b, p. 154, grifo nosso).

A aspiração pela autonomia "não está de graça na presença do indivíduo moderno no mundo, e nas suas relações com os seus semelhantes", contando com os efeitos de angústia produzidos em consequência dessa ideologia (Lacan, 1955-56/1985b, p. 154). Por esse motivo, Lacan acena que "a existência de um discurso permanente de liberdade parece... indiscutível no indivíduo moderno" (1955-56/1985b, p. 154, grifo nosso). Enfim, a busca pela autonomia e a impossibilidade dessa realização é identificada pela teoria lacaniana como um discurso alienante.

\section{Considerações Finais}

Nesse artigo, consideramos que a psicanálise de Freud e Lacan denunciam a consistência almejada pelo discurso da autonomia, revelando seu aspecto de delírio, a partir de três argumentos. Em primeiro lugar, se por autonomia entendemos a capacidade de ser autossuficiente, o que a experiência analítica revela é a impossibilidade desse projeto, na medida em que o sujeito é marcado por uma falta estrutural e pela dependência visceral ao campo do Outro. Essa falta impede a satisfação absoluta e, a reboque, a suficiência do sujeito. Por este motivo, a falta, que revela um furo, um buraco, uma incompletude da estrutura, é, na verdade, causa do desejo do sujeito, por definição um antônimo de sua autossuficiência.

Em segundo lugar, a ideia de autonomia, conforme vimos, relaciona-se com a de indivíduo. A descoberta freudiana coloca em xeque esta noção, uma vez que não há neste campo a proposta de um sujeito solipsista. $\mathrm{O}$ indivíduo somente poderia ser identificado ao eu se abstraísse e excluísse toda a vida inconsciente que o atravessa e o determina, o que para a psicanálise é impossível, já que o eu carrega, ele também, uma parte inconsciente. Em outras palavras, se o eu não é senhor em sua própria morada, o indivíduo não responde à totalidade das experiências que vive: ele é perpassado por desejos inconscientes, é constituído por traços identificatórios que não escolhe, é pressionado por ideais e valores de que não se dá conta. Enfim, ambos - eu e indivíduo - são vividos pelo inconsciente. 
O terceiro argumento diz respeito à etimologia da palavra. Autonomia significa produzir suas próprias normas, em detrimento de normas externas (Lalande, 1999). A teoria tanto freudiana quanto lacaniana indica que, pelo contrário, a constituição psíquica envolve a submissão à lei. A proibição do incesto e a função paterna são algumas das figuras que essas teorias destacam como sendo fundamentais para o processo de subjetivação, levando ao conflito edípico e, por fim, à agregação aos laços sociais. Nesse sentido, o sujeito é constituído por uma lei que ele não criou e nem escolheu acatar, e é essa lei que, ao barrar a relação fusional entre a mãe e a criança, leva esta última a poder se constituir como ser desejante.

Observa-se, em todos os três argumentos, a presença do inconsciente e do desejo como conceitos que insistem em colocar em suspeita a proposta da autonomia. Na medida em que a cultura contemporânea traz, conforme vimos, a convergência de duas ideias opostas em um mesmo movimento - isto é, um imperativo à autonomia -, torna-se, mais do que nunca, necessário à psicanálise denunciar esse projeto e explicitar as suas tensões internas.

A crítica a este projeto de um ideal de autonomia tão presente na subjetivação contemporânea convoca o psicanalista a se posicionar em sua prática na escuta do sofrimento daqueles acossados pela obrigação de serem autônomos. Em sua ética, o psicanalista não abre mão de encontrar como aliados os conceitos de inconsciente e de desejo.

\section{Referências}

Adorno, T., \& Horkheimer, M. (1985). Dialética do esclarecimento: Fragmentos filosóficos. Rio de Janeiro: Jorge Zahar. (Obra original publicada em 1947)

Baudrillard, J. (2008). A sociedade de consumo. Portugal: Edições 70. (Obra original publicada em 1970)

Beck, U. (2010). Sociedade de risco: Rumo a uma outra modernidade. São Paulo, SP: Editora 34. (Obra original publicada em 1986)

Debord, G. (1992). La société du spectacle. Paris: Gallimard. (Obra original publicada em 1967)

Descartes, R. (2005). Meditações Metafísicas. São Paulo: Martins Fontes. (Obra original publicada em 1641)

Deleuze, G. (1992). Post-scriptum sobre as sociedades de controle. In G. Deleuze, Conversações (pp. 219-226). Rio de Janeiro: Editora 34. (Obra original publicada em 1972) 
Dumont, L. (1983). Essai sur l'individualisme: Une perspective anthopologique sur l’idéologie moderne. Paris: Le Seuil.

Ehrenberg, A. (1998). La Fatigue d'être soi: Dépression et société. Paris: Odile Jacob.

Ehrenberg, A. (2010). La société du malaise. Paris: Odile Jacob.

Engels, F., \& Marx, K. (2008). Manifesto Comunista. São Paulo: Boitempo. (Obra original publicada em 1848)

Foucault, M. (1987). Vigiar e punir: Nascimento da prisão. Petrópolis, RJ: Vozes. (Obra original publicada em 1975)

Foucault, M. (2008). Nascimento da biopolítica: Curso dado no Collège de France. São Paulo: Martins Fontes. (Obra original publicada em 1978-79)

Freud, S. (1996). Uma dificuldade no caminho da psicanálise. In S. Freud, Edição standard brasileira das obras psicológicas completas de Sigmund Freud (Vol. 17, pp. 143-155). Rio de Janeiro: Imago. (Obra original publicada em 1917)

Harvey, D. (2008). O neoliberalismo: História e implicações. São Paulo: Edições Loyola.

Hoffmann, C. (2005). 'Eu' devo assumir a responsabilidade do inconsciente. Ágora, 8(1), 4146. doi: 10.1590/S1516-14982005000100003

Lacan, J. (1985a). O Seminário, livro 2: O eu na teoria de Freud e na técnica da psicanálise. Rio de Janeiro: Jorge Zahar Editor. (Obra original publicada em 1954-55)

Lacan, J. (1985b). O Seminário, livro 3: As psicoses. Rio de Janeiro: Jorge Zahar. (Obra original publicada em 1955-56)

Lacan, J. (1986). O seminário, livro 1: Os escritos técnicos de Freud. Rio de Janeiro: Zahar Editora. (Obra original publicada em 1953-54)

Lacan, J. (1992). O Seminário, livro 8: A transferência. Rio de Janeiro: Jorge Zahar. (Obra original publicada em 1960-61)

Lacan, J. (1998a). Estágio do espelho como formador da função do eu. In J. Lacan, Escritos (pp. 100-126). Rio de Janeiro: Zahar. (Obra original publicada em 1949)

Lacan, J. (1998b). A ciência e a verdade. In J. Lacan, Escritos (pp. 869-892). Rio de Janeiro: Jorge Zahar. (Obra original publicada em 1965)

Lalande, A. (1999). Vocabulário técnico e Crítico da Filosofia. São Paulo: Martins Fontes.

Lasch, C. (1991). The culture of narcissism: American life in an age of diminishing expectations. New York: Norton. (Obra original publicada em 1979)

Lemos, A. (2016). Cibercultura: Tecnologia e vida social na cultura contemporânea. Porto Alegre: Sulina. 
Morin, E. (2005). Para além do iluminismo. Cultura e Sociedade. Revista FAMECOS, 12(26), 24-28. doi: 10.15448/1980-3729.2005.26.3299

\section{Endereço para correspondência}

\section{Suéllen Pessanha Buchaúl}

Pontifícia Universidade Católica do Rio de Janeiro

Departamento de Psicologia

Rua Marquês de São Vicente, 225, Gávea, Rio de Janeiro - RJ, Brasil. CEP 22543-900

Endereço eletrônico: sbuchaul@yahoo.com.br

\section{Maria Isabel Fortes}

Pontifícia Universidade Católica do Rio de Janeiro

Departamento de Psicologia

Rua Marquês de São Vicente, 225, Gávea, Rio de Janeiro - RJ, Brasil. CEP 22543-900

Endereço eletrônico: mariaisabelfortes@gmail.com

Recebido em: 28/11/2019

Reformulado em: 27/11/2020

Aceito em: 01/12/2020

\section{Notas}

* Psicanalista, doutoranda em Psicologia Clínica (PUC-Rio) e mestre em Teoria Psicanalítica (UFRJ), bolsista de doutorado pela CAPES.

** Psicanalista, professora Adjunta da Pós-graduação em Psicologia Clínica (PUC-Rio), bolsista de produtividade do CNPq.

Financiamento: Primeira autora: bolsa de doutorado pela CAPES. Segunda autora: bolsa de produtividade pelo CNPq.

Este artigo de revista Estudos e Pesquisas em Psicologia é licenciado sob uma Licença Creative Commons Atribuição-Não Comercial 3.0 Não Adaptada. 